\title{
Genetic, epigenetic and transcriptional comparison of esophagus tumor-associated and adjacent normal myofibroblasts
}

\author{
ILDIKÓ HULIÁK ${ }^{1}$, LÁSZLÓ BODAI ${ }^{1}$, MÁTYÁS CZEPÁN ${ }^{2}$, DÁVID KOVÁCS ${ }^{1}$, ANIKÓ SZABÓ ${ }^{1,3}$, \\ LÁSZLÓ TISZLAVICZ ${ }^{4}$, GYÖRGY LÁZÁR ${ }^{5}$, ZOLTÁN RAKONCZAY Jr ${ }^{2,6}$, \\ PÉTER HEGYI $^{2,7}$, IMRE MIKLÓS BOROS ${ }^{1,3}$ and MÓNIKA KIRICSI ${ }^{1}$ \\ ${ }^{1}$ Department of Biochemistry and Molecular Biology, University of Szeged, Szeged H-6726; \\ ${ }^{2}$ First Department of Medicine, University of Szeged, Szeged H-6720; ${ }^{3}$ Institute of Biochemistry, \\ Biological Research Center of the Hungarian Academy of Sciences, Szeged H-6726; \\ Departments of ${ }^{4}$ Pathology, ${ }^{5}$ Surgery and ${ }^{6}$ Pathophysiology, University of Szeged, Szeged H-6720; \\ ${ }^{7}$ MTA-SZTE Lendület Translational Gastroenterology Research Group, Szeged H-6720, Hungary
}

Received May 2, 2018; Accepted November 13, 2018

DOI: 10.3892/or.2018.6909

\begin{abstract}
Myofibroblasts (MFs) are present in healthy tissues and are also key components of the tumor microenvironment. In the present study a comparative analysis of MFs obtained from various gastrointestinal tumor tissues and from tumor-adjacent normal tissues of cancer patients was performed, with the aim to evaluate differences in MF morphology, gene expression profile and function. The goal was to correlate the observed morphological and functional variations with the underlying genetic and epigenetic backgrounds. The mutation frequency of MFs was assessed by next generation sequencing. The transcript levels of cancer-specific genes were determined by TaqMan array and quantitative polymerase chain reaction. Epigenetic modifications were analyzed by immunocytochemistry and western blotting. The migratory capacity of MFs was assessed by scratch assay, whereas matrix metalloproteinase expression and activity were obtained by quantitative polymerase chain reaction and zymography. The results of the present study demonstrate that MFs were present in an increased number and with altered morphology in tumor samples compared with the healthy tissue. Although the detected number of mutations in tumor-associated and normal tissue-derived MFs did not differ markedly, shifts in the level of specific acetylated and methylated histone proteins, namely decreased levels of trimethylated H3K9 and acetylated H4K16 were demonstrated in tumor-associated MFs.
\end{abstract}

Correspondence to: Dr Mónika Kiricsi, Department of Biochemistry and Molecular Biology, University of Szeged, Közép fasor 52, Szeged H-6726, Hungary

E-mail: kiricsim@bio.u-szeged.hu

Key words: tumor-associated myofibroblast, gastrointestinal tumor, epigenetics, next-generation sequencing, matrix metalloproteases, migration
Transcript levels of several tumor-specific genes involved in metastasis, regulation of cellular growth, apoptosis, as well as in hypoxia-angiogenesis were altered in tumor-derived $\mathrm{MF}$ cultures. Increased mRNA levels were obtained and activity of matrix metalloproteases in tumor-derived MFs and these cells also exhibited a higher migratory capacity compared with the normal MFs. In summary, the results of the present study indicate that tumor-associated MFs display an altered phenotype compared with healthy tissue derived counterparts. The results imply that epigenetic rather than genetic alterations are associated with the development of the distinct expressional and functional features, which define this MF phenotype in the tumor microenvironment.

\section{Introduction}

The tumor microenvironment is now recognized as a critical participant in cancer progression (1-4). In epithelial tumors, out of the various types of stromal cells, cancer-associated fibroblasts (CAFs) are the predominant subset. Of CAFs, myofibroblasts (MFs) constitute the most abundant subtype, occupying the majority of this particular niche $(5,6)$. In MFs the characteristic features of smooth muscle cells and fibroblasts are combined, as MFs acquire the ability to contract due to the de novo expression of smooth muscle actin ( $\alpha$-SMA) and by the assembly of novel stress fibers $(7,8)$, and also maintain the extracellular matrix (ECM) synthesizing and secreting functions of fibroblasts. MFs are also mediators of tumor development and metastasis. However, it is still under debate whether their stimulating effects on cancer cell invasion are executed directly through paracrine interactions with tumor cells or they promote cancer cell spreading indirectly by rendering the ECM more permissive for dissemination via remodeling (9-12). MFs express cytokines, chemokines, growth factors, different collagens, fibronectin, various adhesion molecules and matrix metalloproteases (MMPs), and secrete these molecules directly or within exosomes into the surrounding extracellular milieu $(13,14)$. It has been proposed 
that this secretome alone would not be competent enough to trigger cancer cell invasion, but it is definitely sufficient for intensive paracrine dialogues between stromal cells $(9,10)$. On the other hand, as MFs can modulate the composition and deregulate the biomechanical features of stromal ECM; in part by overproducing various MMPs, which will ultimately degrade the matrix and sever cell-matrix interactions. These MF-induced actions would undoubtedly favour cell mobilization and contribute to cancer progression $(11,15)$. In fact, several studies verified that the appearance of MMPs in the tumor microenvironment is associated with increased cancer aggressiveness and bad prognosis $(16,17)$.

Due to the pivotal role of stromal MFs in tumor development and progression, targeting MFs may be a viable approach to fight cancer invasion and metastasis. Nevertheless, prior to establishing MF-targeting clinical trials, it is essential to understand the major genetic, transcriptional and functional features of MFs residing in tumor-affected as well as in normal tissues. This knowledge is absolutely necessary in order to identify the key mechanisms that primarily govern the contribution of MFs in tumor invasion $(10,18)$. In line with this, a comparative study was performed on matched pairs of primary MF cultures, isolated from cancerous specimens and from the tumor-adjacent normal tissues of patients diagnosed with different gastrointestinal cancers. Detailed knowledge on the modulated MF behavior of the human esophagus or other gastrointestinal regions is relevant not only in cancer progression and invasion, but also in various injuries, inflammation, repair as well as in gastro-esophageal reflux disease (19).

Therefore, pure MF cell cultures were first established then genetic polymorphisms were analyzed, epigenetic marks and gene expression profiles of normal tissue- and tumor-derived MFs with a special emphasis on genes involved in tumorigenesis, invasion, matrix remodeling, cell migration or proliferation were compared. The present study's particular focus was to reveal whether any notable genetic, epigenetic or expressional variations could be identified that would account for the tumor promoting effects of tumor-associated MFs. Concomitantly, targeted genome analysis of the esophageal tumor sample was also conducted.

\section{Materials and methods}

Chemicals and solutions. General laboratory reagents were from Sigma-Aldrich (Merck KGaA, Darmstadt, Germany) and Molar Chemicals Kft (Budapest, Hungary). Cell culture media and associated reagents were from Sigma-Aldrich (Merck $\mathrm{KGaA}$ ), specific reagents for polymerase chain reaction (PCR) were from Thermo Fisher Scientific, Inc., (Waltham, MA, USA).

Ethics. The present study was approved by the Ethics Committee of the University of Szeged, (Szeged, Hungary). All patients gave informed consent.

Patients. Esophageal as well as cecum, sigmoid colon and rectum resections were performed on patients diagnosed with gastrointestinal cancer at the Department of Surgery, University of Szeged. The esophageal cancer patient was a 71-year-old male, the cecum cancer patient was a 69-year-old female, sigmoid colon cancer patient was a 71-year-old male and the rectum cancer patient was a 65-year-old female. The patients were recruited between January 2007 and May 2010. The status of the patients was evaluated regarding clinicopathological features, histopathological parameters, the stage, grade as well as histological type of the tumor. Lymphatic vessel or vascular invasion and positive margins of resections were also assessed.

Tissue specimens. Tissue specimens were obtained intraoperatively during cancer resection. Specimens were taken from the tumor tissues and also from the adjacent normal area (at least 3-4 cm distant from the tumors).

Tissue specimens were evaluated following routine pathology procedures. These included passage from formalin into paraffin, sectioning, staining the $4-\mu \mathrm{m}$ thick sections with hematoxylin and eosin ( $5 \mathrm{~min}$, room temperature), Giemsa technique (15 min, room temperature) and periodic acid-Schiff technique/Alcian blue (30 min, room temperature). Finally, immunostaining for $\alpha$-SMA (ab: cat. no. ms-113; 1:800; Thermo Fisher Scientific, Inc.), vimentin (ab: cat. no. rm-9120; 1:200; Thermo Fisher Scientific, Inc.) and desmin (ab: cat. no. ms-376; 1:100; Thermo Fisher Scientific, Inc.) was carried out using EnVision Flex system (Dako; Agilent Technologies, Inc., Santa Clara, CA, USA) according to the manufacturer's protocol. Sections were counterstained with hematoxylin at room temperature for $1 \mathrm{~min}$. All slides were stained simultaneously using a computer-controlled autostainer (Ventana BenchMark Ultra, Ventana Medical Systems, Inc., Tucson, AZ, USA).

The images captured for histopathological assessment using a Zeiss Axiocam 506 color microscope and were analyzed using ImageJ 1.4.3.67 software (National Institutes of Health, Bethesda, MD, USA). Densitometry was performed to determine brown color intensity. Images were converted to RGB format and color-based thresholding was set as follows: Hue $0-136$, saturation 57-255, brightness $0-255$. On 8-bit images threshold was adjusted to $0-242$, then particle analysis was performed.

Establishment of MF cultures. The isolation and culturing of normal as well as tumor-derived MFs was performed as described previously by Czepan et al (20). Briefly, normal tissue specimens and esophageal tumor tissue as well as cecum, sigmoid colon or rectum carcinoma samples were washed with $1 \mathrm{mM}$ DTT, incubated four times with $1 \mathrm{mM}$ EDTA solution for $30 \mathrm{~min}$, then placed into RPMI (Merck KGA) selection medium supplemented with $10 \%$ fetal bovine serum (FBS, Merck KGA); $1 \%$ penicillin-streptomycin, $2 \%$ antibiotic-antimycotic solution. Following reaching confluence, the cells were trypsinized ( $0.25 \%$ trypsin-EDTA) and were transferred into growth medium [Dulbecco's modified Eagle's medium (DMEM, Merck KGA) supplemented with 4 mM L-glutamine, $10 \% \mathrm{FBS}, 1 \%$ amino acid solution, $1 \%$ penicillin-streptomycin and $2 \%$ antibiotic-antimycotic solution]. Cells were cultured in $5 \% \mathrm{CO}_{2}$ atmosphere at $37^{\circ} \mathrm{C}$. Aliquots were frozen in liquid nitrogen and used in the following experiments with care to minimize passage numbers. To monitor the purity of MF cultures, cells were stained for MF markers $\alpha$-SMA and vimentin as previously described (20). 
Immunocytochemistry. For the detection of histone modifications by immunostaining, $2 \times 10^{4}$ cells were seeded onto chamber slides (BD Biosciences, Franklin Lakes, NJ, USA) and were allowed to adhere overnight. Cells were fixed using $4 \%$ paraformaldehyde for $20 \mathrm{~min}$ at room temperature, permeabilized by adding PBS supplemented with $0.3 \%$ Triton X-100. Non-specific protein binding sites were blocked in 5\% bovine serum albumin (BSA; Sigma-Aldrich; Merck KGaA) containing PBS and finally, cells were incubated with primary antibodies for $2 \mathrm{~h}$ at room temperature. The used primary antibodies, their sources and the applied dilutions were: Pan-acetylated histone 3 (H3)-specific antibody (Bio-Rad Laboratories, Inc., Hercules, CA, USA); cat. no. AHP412; diluted in 1:300 with 1\% BSA containing PBS), anti-lysine 9 acetylated $\mathrm{H} 3$ antibody (Abcam, Cambridge, UK; cat. no. Ab4441; 1:750), antibody against H3K18ac (Abcam; cat. no. Ab1199; 1:500), anti-H3K14ac antibody (Sigma-Aldrich; Merck KGaA) cat. no. 06-911; 1:450), antibody specific for lysine 8 acetylated histone 4 (Abcam; cat. no. Ab1760; 1:400), H4K12ac-specific antibody (Abcam; cat. no. Ab1761; 1:300), antibody against H4K16ac (Abcam; cat. no. Ab1762; 1:300) and antibody to detect pan-acetylated H4 (Sigma-Aldrich; Merck KGaA; cat. no. 06-598; 1:500). Antibodies specific for $\mathrm{H} 3$ di- and trimethylated at lysine 9 were from Upstate (Merck KGaA; cat. no. 07-521) and Abcam (cat. no. Ab8898) and used in 1:750 and 1:500 dilutions, respectively. Samples were incubated with the secondary antibody (Alexa Fluor 555-conjugated anti-rabbit IgG; Molecular Probes; Thermo Fisher Scientific, Inc.) at room temperature in the dark, for $1 \mathrm{~h}$. For DNA labeling, 4,6-diamino-2-phenylindole (DAPI) staining was performed (dilution 1:3,000 in PBS solution, for $5 \mathrm{~min}$ ). Following extensive washing in PBS, slides were covered with fluoromount mounting medium (Sigma-Aldrich; Merck KGaA). Quantification of fluorescence intensity was performed using ImageJ 1.4.3.67 software (National Institute of Health, Bethesda, MD, USA). Corrected total cell fluorescence (CTCF) was calculated based on fluorescence values from $\sim 30$ cells/sample according to the following formula: $\mathrm{CTCF}=$ integrated density-(area of selected cell x mean fluorescence of background readings).

Variant analysis. DNA variant analysis of selected tumor genes was performed by targeted sequencing on DNA samples derived from tumor-associated and normal MFs and from cells of the tumor mass. DNA was prepared using Macherey-Nagel NucleoSpin Tissue columns according to the manufacturer's protocol. Samples were quantitated by Qubit dsDNA BR assay kit (Thermo Fisher Scientific, Inc.) with a Qubit 2.0 fluorimeter. For each sample, $50 \mathrm{ng}$ DNA was used to prepare Illumina sequencing libraries using Illumina TruSight Rapid Capture kit (Illumina, Inc., San Diego, CA, USA) with TruSight Cancer sequencing panel. The TruSight Cancer panel targets 94 genes and sites of 284 single nucleotide polymorphisms (SNPs) associated with tumors. The gene list of the TruSight Cancer panel is available online on the manufacturer's website (https://emea. illumina.com/content/dam/illumina-marketing/documents/products/gene_lists/gene_list_trusight_cancer.xlsx). Sequencing libraries were prepared by the TruSight Rapid Capture workflow and quality tested by capillary electrophoresis on an Agilent Bioanalyzer 2100 instrument with Agilent High Sensitivity
DNA chip (Agilent Technologies). Pooled mixtures of indexed libraries were denatured and sequenced with Illumina MiSeq using Reagent kit V2-300. Variants were called by MiSeq Report (MSR) enrichment workflow of the BaseSpace cloud computing environment. Vcf files containing the identified variants were annotated using Illumina VariantStudio 2.1.46 software (Illumina, Inc.) with the following annotation sources: Variant Effect Predictor, v2.8; 1000 Genomes (April 2012 v3); Cosmic (v65); ClinVar (September 5, 2013); dbSNP (v137); NHLBI Exome Variant Server (vESP6500SI-V2); USCS (hg19).

RNA extraction. Total RNA was isolated from confluent MF cultures with TRIzol reagent (Invitrogen; Thermo Fisher Scientific, Inc.) using the manufacturer's protocol, followed by removal of DNA contamination with DNase I (Thermo Fisher Scientific, Inc.). Total RNA from Hker E6SFM human keratinocytes was a gift from Dr. Vilmos Tubak (Creative Laboratory Ltd., Szeged, Hungary). Quality of total RNA was assessed using Agilent Bioanalyzer 2100 (Agilent Technologies).

TaqMan low-density gene expression array. For gene expression the mRNA levels of 190 genes were analyzed simultaneously by reverse transcription-quantitative (RT-q) PCR by TaqMan Low Density Array (TLDA; Applied Biosystems; Thermo Fisher Scientific, Inc.) using 384-well microfluidic cards. Each sample was loaded in duplicates. In the TLDA experiments 600 ng RNA was reverse transcribed with a High Capacity Reverse Transcription kit (Thermo Fisher Scientific, Inc.) according to the manufacturer's protocol and cDNAs were mixed with TaqMan Universal PCR Master mix (Thermo Fisher Scientific, Inc.). UD-GenoMed Medical Genomic Technologies Company (Debrecen, Hungary) has performed PCR amplifications using an ABI PRISM 7900HT real-time PCR system (Thermo Fisher Scientific, Inc.). PCR reaction cycles were: $2 \mathrm{~min}$ at $50^{\circ} \mathrm{C}$ and $10 \mathrm{~min}$ at $94.5^{\circ} \mathrm{C}$, followed by 40 cycles of $30 \mathrm{sec}$ at $97^{\circ} \mathrm{C}$ and $1 \mathrm{~min}$ at $59.7^{\circ} \mathrm{C}$.

The genes included in the analysis were manually selected from TaqMan Gene Sets (https://products.appliedbiosystems. com/ab/en/US/adirect/ab?cmd=catNavigate2\&catID=604535). The expression levels were normalized to five internal controls; GAPDH, $\beta$-2-microglobulin, $\beta$-actin, 18S RNA and glucuronidase- $\beta$. Increases or decreases of 2 -fold in the expression levels were considered as significant alterations.

Quantitative and conventional RT-PCR. For quantitative and conventional RT-PCR reactions first strand cDNA was synthesized from $1 \mu \mathrm{g}$ total RNA obtained from MFs and from Hker E6SFM human keratinocytes used as control, with random hexamer primers using TaqMan Reverse Transcription Reagent (Applied Biosystems; Thermo Fisher Scientific, Inc.) according to the manufacturer's protocol.

Conventional PCR was carried out using GeneAmp PCR System 9700 (Thermo Fisher Scientific, Inc.). Thermal cycling was performed as follows: $5 \mathrm{~min}$ at $95^{\circ} \mathrm{C}, 30$ cycles of $95^{\circ} \mathrm{C}$ for $20 \mathrm{sec}, 60^{\circ} \mathrm{C}$ for $40 \mathrm{sec}$ and $72^{\circ} \mathrm{C}$ for $45 \mathrm{sec}$. PCR products (10 $\mu \mathrm{l}$ of $30 \mu \mathrm{l}$ total products per lane) were resolved on $2 \%$ agarose gel and visualized using ethidium-bromide.

qPCR reactions were carried out in duplicates in an ABI PRISM 7500 real-time thermocycler and Thermo 
PikoReal 96 Real-Time PCR system using SYBR-Green chemistry (Maxima SYBR Green qPCR Master Mix 2X; K0252, Thermo Fisher Scientific, Inc.). The thermocycling conditions were the following: $1 \mathrm{X}\left(95^{\circ} \mathrm{C}, 5 \mathrm{~min}\right) ; 40 \mathrm{X}\left(95^{\circ} \mathrm{C}\right.$, $\left.15 \mathrm{sec}-60^{\circ} \mathrm{C}, 1 \mathrm{~min}\right)$. Individual quantification cycle $(\mathrm{Cq})$ values were normalized to $\mathrm{Cq}$ values of an internal control gene (18S ribosomal RNA). The tumor-associated samples were compared with the appropriate controls following normalization. Alterations in the expression levels were calculated by the $2^{-\Delta \Delta \mathrm{Cq}}$ method (21). Primer sequences were as follows: Matrix metalloproteinase (MMP)1-F: 5'-GAT GTG GAG TGC CTG ATG TG-3'; MMP1-R: 5'-CTG CTT GAC CCT CAG AGA CC-3'; MMP2-F: 5'-ATG ACA GCT GCA CCA CTG AG-3', MMP2-R: 5'-ATT TGT TGC CCA GGA AAG TG-3', MMP3-F: 5'-GGC AGT TTG CTC AGC CTA TC-3', MMP3-R: 5'-TCA CCT CCA ATC CAA GGA AC-3'; MMP10-F: 5'-CAT ACC CTG GGT TTT CCT CCA A-3', MMP10-R: 5'-GTC CGC TGC AAA GAA GTA TGT TTT C-3'; MMP12-F: 5'-GAT GCA CGC ACC TCG ATG T-3'; MMP12-R: 5'-GGC CCC CCT GGC ATT-3', 18 SRNA-F: 5'-AAA CGG CTA CCA CAT CCA AG-3'; 18 SRNA-R: 5' CGC TCC CAA GAT CCA ACT AC-3'.

Protein extraction and western blotting. For preparation of whole cell protein extracts, confluent MF cultures were washed with PBS, cells were collected by scraping and lysed in loading buffer [60 mM Tris (pH 6.8), $2 \%$ SDS, $10 \%$ glycerol, $5 \% \beta$-mercaptoethanol, $0.002 \%$ bromophenolblue]. Total protein concentration of the samples was assessed by bicinchoninic acid protein assay kit (Thermo Fisher Scientific, Inc.) prior adding bromophenolblue. A total of $15 \mu \mathrm{g}$ protein of each sample was separated by SDS-PAGE on 15\% gels and transferred onto nitrocellulose membrane (Amersham; GE Healthcare, Chicago, IL, USA). Membranes were incubated first in 5\% non-fat milk (in Tris-buffered saline supplemented with $0.5 \%$ Tween-20) to block non-specific binding sites then with primary anti-histone antibodies specific for H4K16ac (Abcam; cat. no. Ab1762; 1:500) and H3K9me3 (Abcam; cat. no. Ab8898; 1:750). Detection of H4 was used to verify equal loading. For this anti-H4 antibody (Abcam; cat. no. mab31827) was applied in 1:8,000 dilution. Incubation with horseradish peroxidase-conjugated $\mathrm{IgG}$ secondary antibodies (Dako; Agilent Technologies, Inc., anti-rabbit IgG; cat. no. P0448; 1:2,000 for modified histones and anti-mouse IgG, cat. no. P0260; 1:10,000 for H4) was performed at room temperature, for $50 \mathrm{~min}$. Blots were developed with chemiluminescent HRP reagent (EMD Millipore, Billerica, MA, USA).

Assessment of MMP activity by gelatine zymography. The activities of the two gelatinolytic MMPs (MMP2 and MMP9) in cell lysates and in cell media were examined with gelatine zymography. MFs were lysed in $50 \mathrm{mM}$ Tris $\mathrm{pH} 7.4$, $0.2 \%$ Triton X-100 buffer by freeze-thawing in liquid $\mathrm{N}_{2}$ and pressing through a $23 \mathrm{G}$ needle. Following centrifugation $\left(17,000 \times \mathrm{g}, 10 \mathrm{~min}, 4^{\circ} \mathrm{C}\right)$, total protein concentration was measured by the Bradford method (Bio-Rad Laboratories, Inc.). To detect gelatinase activity in culture media, MFs were grown to $100 \%$ confluence in $75 \mathrm{~cm}^{2}$ flasks. Cells were serum starved for $24 \mathrm{~h}$, then media were collected on ice and the proteins were precipitated by trichloroacetic acid in the presence of sodium-deoxycholate. The pellet was collected by centrifugation $\left(17,000 \mathrm{x} \mathrm{g}, 30 \mathrm{~min}, 4^{\circ} \mathrm{C}\right)$, washed with acetone and re-suspended in water (22).

A total of $10 \mu \mathrm{g}$ protein samples were resolved on $10 \%$ native PAGE co-polymerized with gelatin $(2.5 \mathrm{mg} / \mathrm{ml}$, type A from porcine skin; Sigma-Aldrich; Merck KGaA). Following electrophoresis, gels were washed 3 times for 20 min with $2.5 \%$ Triton X-100 solution and incubated for $20 \mathrm{~h}$ at $37^{\circ} \mathrm{C}$ in buffer containing $50 \mathrm{mM}$ Tris- $\mathrm{HCl} \mathrm{pH} \mathrm{7.4,150} \mathrm{mM}$ $\mathrm{NaCl}, 5 \mathrm{mM} \mathrm{CaCl}{ }_{2}$ and $0.05 \% \mathrm{NaN}_{3}$. Following incubation, gels were stained with Coomassie Brilliant Blue for $1 \mathrm{~h}$ and at room temperature and destained in $30 \%$ ethanol, $10 \%$ acetic acid solution.

Migration assay. A total of $2 \times 10^{5}$ cells were seeded onto six-well plates and allowed to grow overnight in growth medium. On the following day the confluent monolayer was gently scratched by a P2 tip in the middle of the well. Wounds were measured and images were captured under an inverted light microscope. Cultures were incubated at $37^{\circ} \mathrm{C}$ for $24 \mathrm{~h}$ and migration of the cells was evaluated by counting the number of cells, which migrated into the wound area (20). The motility of tumor-derived MFs was expressed as percentage of the control MFs.

Statistics. Data are presented as mean \pm standard error of the mean. Experiments were repeated 3 times using 3 independent replicates. Statistical significance was determined using SigmaPlot Software version 12.0 (Systat Software, San Jose, CA, USA) with Student's t-test, Mann-Whitney U test or analysis of variance followed by Tukey's HSD post hoc multiple comparison test.

\section{Results}

Histological analysis of MFs in normal tissue and in the esophageal tumor of a patient. The patient involved in the major part of the study is a 71-year-old male with a $42 \times 39 \times 7 \mathrm{~mm}$ esophageal adenocarcinoma, which developed probably on a Barrett's esophagus background. Tumor grading was determined as pT3N1Mx, grade 2-3. Lymphatic and vascular invasion was identified. Sections of esophageal tumor and normal tissue, obtained from the patient, were stained for $\alpha$-SMA, desmin and vimentin to inspect the number, morphology and localization of MFs. Representative $\alpha$-SMA immunostainings on the tissue sections are presented in Fig. 1 (A, normal; B, tumor-derived sample). Intensive brown staining indicates high expression of $\alpha$-SMA, a feature characteristic to MFs. Pericytes and smooth muscle cells also express $\alpha$-SMA, however, these cells can be recognized and distinguished from MFs based on their characteristic morphology and on complementary immunostainings for desmin and vimentin (not shown).

The histological analysis concluded that the number of $\alpha$-SMA- and vimentin-positive cells within the tumor was increased (Fig. 1B). Densitometrically quantified and normalized MF-specific brown color staining revealed significantly elevated $(230 \%)$ color density in tumor-derived sections compared with the color intensity in adjacent normal tissue sections (set as 100\%), indicating higher incidence of MF in 

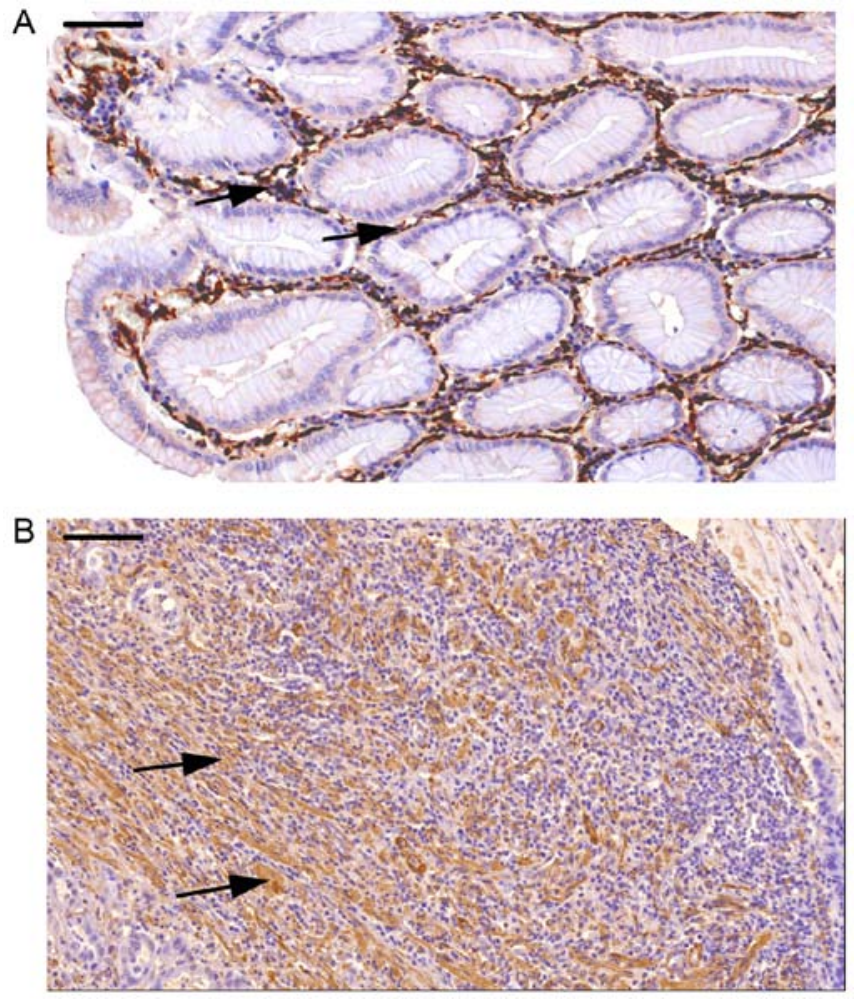

Figure 1. Immunolocalization and morphological rearrangement of tumor-associated MFs. Representative $\alpha$-smooth muscle actin immunostainings of (A) normal and (B) tumor-derived sections are presented. Brown staining highlights MFs, pericytes and smooth muscle cells. MFs (indicated by arrows) are localized mostly around the crypts in the adjacent normal tissue Note that in the tumor the number of MFs is markedly increased, their shape is distorted and their architecture is severely damaged. The scale bar in the left upper corner indicates $100 \mu \mathrm{m}$ for both panels A and B. MF, myofibroblasts.

the tumor-derived sections $(\mathrm{P}<0.001$, Student's $\mathrm{t}$-test, data not shown). Furthermore, the spatial arrangement and distribution of MFs were also markedly different in the tumor environment compared with the normal tissue. MFs were demonstrated mostly around the crypts and were confined to pericryptal and subepithelial localization in normal tissue, whereas in the tumor tissue, apart from the highly elevated number and the greatly distorted shape of MFs, the arrangement of the cells was severely transformed, composing meshwork-like structures embedded in the tumor mass.

Genetic background, epigenetic modifications in MFs and targeted genome analysis of the tumor sample. To identify genetic alterations in MF cells and possible somatic variants in esophagus tumor-derived MFs targeted genome analysis was performed. The exonic sequences of 94 tumor-associated genes and 284 additional sites of tumor-associated SNPs included in the Illumina TruSight Cancer Panel, were determined by next generation deep sequencing. DNA sequences totaling of $255 \mathrm{kbp}$ of samples obtained from normal tissue-derived and tumor-derived MF cells, and also from esophageal tumor tissue were determined. Sequencing data were analyzed and variants of interest were selected following annotation with Illumina VariantStudio software.

It was demonstrated that on the sequenced $255 \mathrm{kbp}$ genomic region normal tissue-derived MFs of this patient carried 277 variants and identical number or variants were present in the tumor-associated MFs, while 282 variants were discovered in tumor tissue samples. Out of the 277 SNPs in MFs 22 (Table I) were predicted to be functionally significant, based on their effect on protein structure, by their ClinVar classification or presence in the COSMIC database, or by their predicted effect on protein function by Sift and/or PolyPhen analysis. These SNPs were located in the ALK receptor tyrosine kinase, BRCA2, epidermal growth factor receptor, ERCC excision repair 5 (ERCC5), exostosin glycosyltransferase 1, FA complementation group I, FERM, ARH/RhoGEF and pleckstrin domain protein 2, HNF1 homeobox A, HRas proto-oncogene, GTPase, mutL homolog 1, mutS homolog 6 (MSH6), PMS1 homolog 2, mismatch repair system component, patched 1, SLX4 structure-specific endonuclease subunit (SLX4), tumor protein p53 (TP53), or TSC complex subunit 2 (TSC2) genes and each were present in a heterozygous state. A total of four genes $E R C C 5, B R C A 2$, MSH6 and SLX4 were affected each by more than one SNP, however, whether these represented mono- or diallelic state of these variants cannot be determined.

Next those variants that were present in lower frequency and only in the esophagus tumor-derived MFs or/and in the esophagus tumor sample but not in the adjacent normal MF samples (Table II) were identified in order to gain information on somatic mutation load in the tumor tissue, and tumor-associated MFs. In the tumor-derived MF samples variants with $5-7 \%$ allele frequency in the enhancer of zeste 2 polycomb repressive complex 2 subunit (EZH2; chr7: 148511066, C>A), TSC2 (chr16: 2120519, C>A) and folliculin (FLCN; chr17: 17119708, T>TG) genes were identified. The SNPs affecting $E Z H 2$ and TSC2 caused missense mutations, the insertion in FLCN causes a frame-shift mutation and is described in the ClinVar and COSMIC database (id: COSM1381204) as a variant associated with the large intestine as primary tumor site. In the tumor tissue variants of the $F A$ complementation group D2 (FANCD2), XPC complex subunit, BRCA1 associated protein 1 and glypican 3 were demonstrated with 2-4\% allele frequency and SNP of TP53 with allele frequency of $14.92 \%$. The TP53 variant (chr17: $7577539, \mathrm{G}>\mathrm{A})$ is present in the ClinVar and COSMIC databases (id: COSM10656) and is associated with Li-Fraumeni syndrome and tumors with various primary sites including the esophagus. The de novo somatic nature of most of these variants is supported by the fact that all of the relevant variants, except for a FANCD2 variant in the tumor sample, have a $0 \%$ global allele frequency in the 1,000 Genomes Project database.

All combined, esophagus tumor-derived MFs demonstrated 3, while the tumor sample exhibited 5 sequence variants not present in normal MFs. The low occurrence of somatic variants in MFs obtained from the tumor tissue and the observation that the normal tissue-derived MFs carried nearly the same numbers of unique somatic mutations suggest that mutation frequency is not elevated greatly in tumor-associated MFs.

As no drastic difference in mutation frequency between tumor-derived MFs and MFs isolated from the normal tissue was detected, it was hypothesized that epigenetic modifications may be involved in the development of the observed morphological alterations, since epigenetic alterations can affect the 


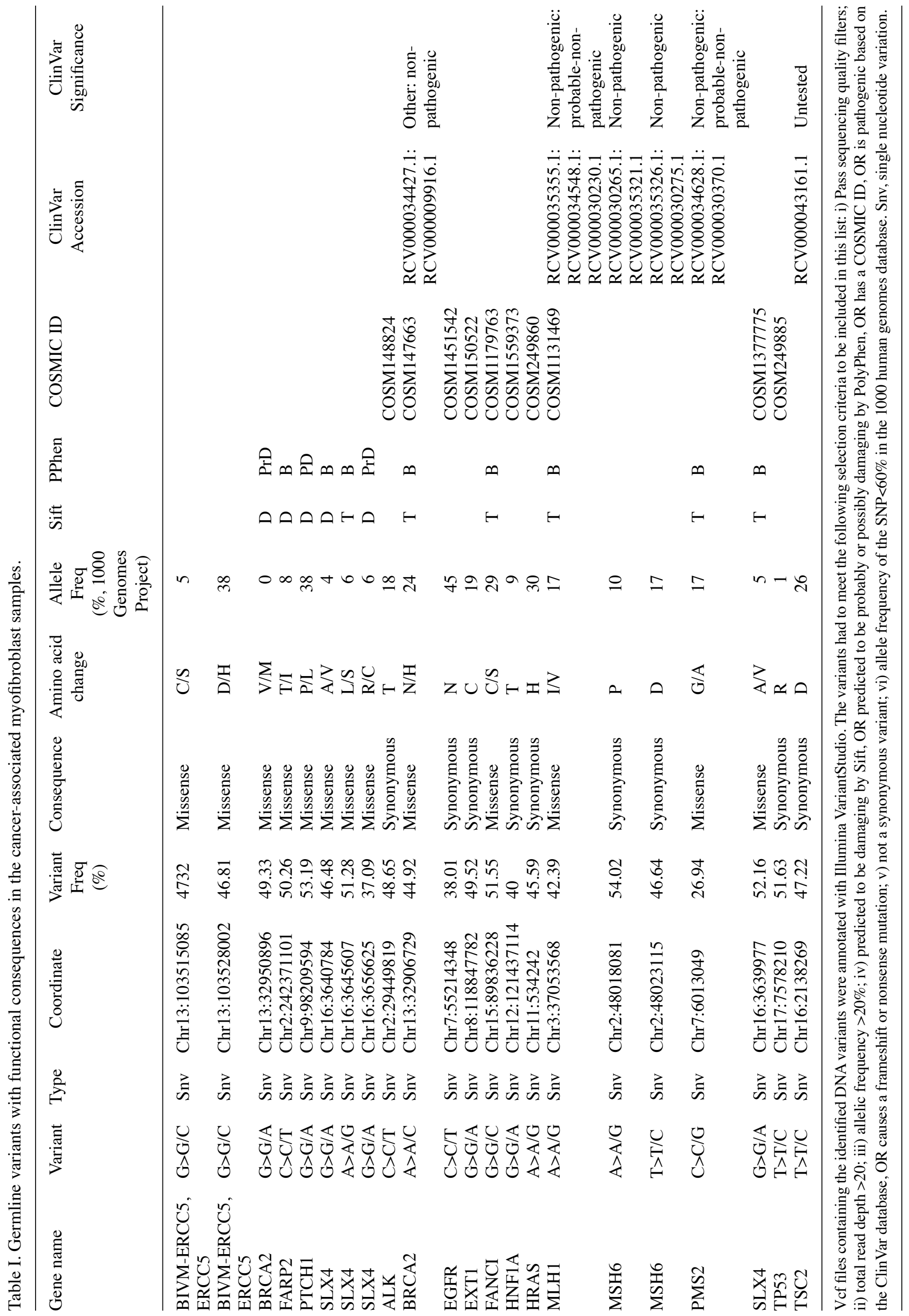




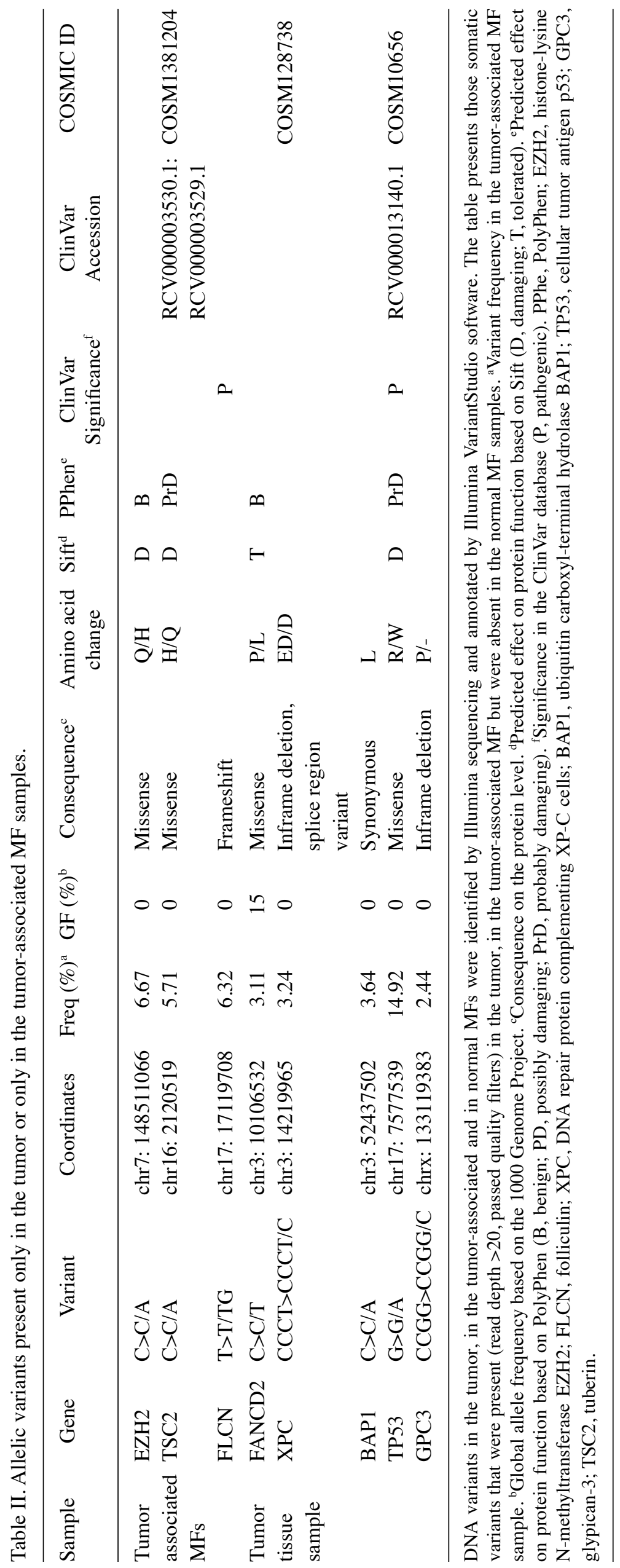


A H3K9me3 $\mathrm{N}$
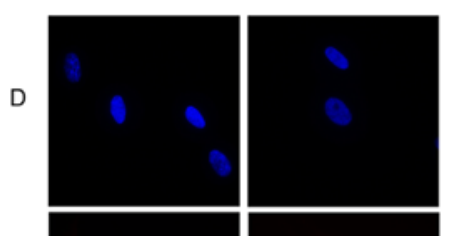

$\mathrm{H}$
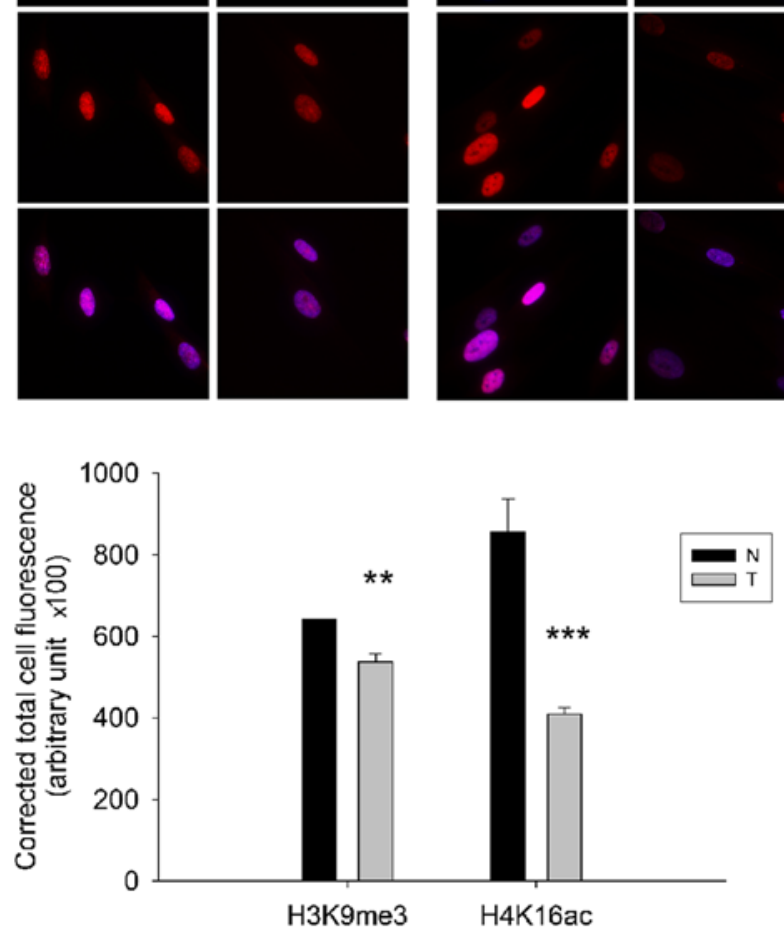

B

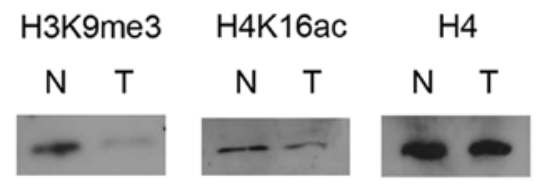

Figure 2. Histone acetylation and methylation profile in tumor-associated and normal myofibroblasts. (A) Representative immunostaining images of $\mathrm{H} 3 \mathrm{~K} 9 \mathrm{me} 3$ and $\mathrm{H} 4 \mathrm{~K} 16 \mathrm{ac}$ modifications and the quantification of the fluorescence intensity (by ImageJ) are presented demonstrating that $\mathrm{H} 3 \mathrm{~K} 9$ trimethylation and $\mathrm{H} 4 \mathrm{~K} 16$ acetylation level was significantly reduced in T compared with $\mathrm{N}$ cells. ${ }^{* *} \mathrm{P}=0.006$ for $\mathrm{H} 3 \mathrm{~K} 9 \mathrm{me} 3$ and ${ }^{* * * *} \mathrm{P}<0.001$ for H4K16ac, Mann-Whitney U test. (B) Immunoblots supported the observations of the immunocytochemistry, indicating lower levels of trimethylated $\mathrm{H} 3 \mathrm{~K} 9$ and acetylated $\mathrm{H} 4 \mathrm{~K} 16$ in the tumor-associated cells. H3K9me3, trimethylated histone 3 lysine 9; H4K16ac, acetylated histone 4 lysine 16; $\mathrm{T}$, tumor-associated; $\mathrm{N}$, normal.

expression profile and ultimately the morphology and the function of tumor-associated MFs. To substantiate this notion, a selected number of epigenetic markers were first examined by immunostaining. MFs were incubated with antibodies specific for pan-acetylated $\mathrm{H} 3$ and $\mathrm{H} 4$ as well as with antibodies recognizing specifically H3K9ac, H3K14ac, H3K18ac, H4K8ac, H4K12ac, H4K16ac, and di- and trimethylated H3K9. Immunostaining revealed significantly decreased global levels of trimethylated H3K9 and acetylated H4K16 ( $<<0.01$; Fig. 2A) in the esophagus tumor-derived MFs compared to the adjacent normal MF cells. Immunoblots verified the results obtained by immunocytochemistry for selected histone modifications, since western blotting also indicated lower levels of trimethylated $\mathrm{H} 3 \mathrm{~K} 9$ and acetylated $\mathrm{H} 4 \mathrm{~K} 16$ in tumor-derived MF cells (Fig. 2B). On the other hand, further differences in global histone modifications between MFs isolated from the tumor and from the adjacent normal tissue were not detected (data not shown).

Transcriptome analysis of tumor-derived and normal MFs. As a further step to compare MFs obtained from normal and esophageal tumor tissue, whether any variations in the expression patterns of selected genes can also be identified was investigated. The mRNA levels of 190 chosen genes were compared on TaqMan low-density gene expression array. In the analysis genes associated with invasion, metastasis development, angiogenesis, oxidative stress and apoptosis were included, as well as genes responsible for signaling pathway components [mitogen activated protein kinase, transforming growth factor (TGF)- $\beta$ and wingless-type MMTV integration site family $(W N T)$ ]. Furthermore, the expression level of ECM elements including different types of collagens, basement membrane components and matrix remodeling factors were also examined.

Results of the arrays revealed that several genes involved in metastasis [C-X-C motif chemokine ligand 12 (CXCL12), endothelin 1 (EDN1), LY6/PLAUR domain containing 3 (LYPD3), $M M P 3$ and plasminogen activator, urokinase (PLAU)], in regulation of cellular growth [cyclin D1 (CCND1), Fos proto-oncogene ( $F O S$ ), mitogen-activated protein kinase kinase kinase 8 (MAP3K8), myostatin (GDF8), uncoupling protein 2 (UCP2) and WNT1-inducible-signaling pathway protein 1 (WISP1)], in apoptosis (BCL2) as well as in hypoxia-angiogenesis [ectonucleotide pyrophosphatase/phosphodiesterase 2 (ENPP2), heme oxygenase 1 (HMOXI) and pleiotrophin (PTN)] demonstrated altered expression in matching MF cultures derived from tumor and from the adjacent normal tissue (Table III). On the other hand, none of the collagen genes included in the TaqMan array (collagen I $\alpha 1$, collagen IV $\alpha 1$ and collagen XV $\alpha 1$ ) or any relevant ECM glycoproteins and proteoglycans exhibited altered expression in tumor-associated MFs compared with the cognate normal controls.

The detected elevated gene expression levels of CCNDI, $U C P 2$ and Wnt signaling pathway member WISPI in tumor-derived MFs suggest a higher proliferation rate which can account for the increased MF cell number within the esophageal tumor mass. In contrast, lower levels of mRNAs corresponding to GDF8, FOS and MAP3K8 in tumor-associated MFs (Table III) were demonstrated.

In tumor-derived MFs higher expression level of metastasis-associated factor endothelin 1, a secreted peptide, which has been demonstrated to stimulate cancer and stromal cell proliferation and migration within the tumor microenvironment was observed. Similarly, elevated gene expression of MMP3 and PLAU was detected in tumor-associated MFs compared to normal tissue-derived MFs (Table III). On the other hand, TaqMan array data indicated lower expression of the chemokine CXCL12 and of LYPD3.

Finally, decreased expression of apoptosis-associated $B C L 2$, as well as of hypoxia-angiogenesis-linked ENPP2, HMOXI and PTN genes were detected in esophagus tumor-derived MFs compared with normal counterparts (Table III). 
Table III. Increased or decreased expression of specific genes in tumor-associated versus adjacent normal MFs analyzed by TaqMan array.

\begin{tabular}{|c|c|c|}
\hline 1. Apoptosis & Symbol & $\log 2$ change \\
\hline B-cell CLL/lymphoma 2 & BCL2 & -1.05 \\
\hline 2. Hypoxia-angiogenesis associated & Symbol & $\log 2$ change \\
\hline Ectonucleotide pyrophosphatase/phosphodiesterase 2 (autotaxin) & ENPP2 & -3.13 \\
\hline Heme oxygenase (decycling) 1 & HMOX1 & -1.37 \\
\hline Pleiotrophin & PTN & -1.28 \\
\hline 3. Metastasis associated & Symbol & $\log 2$ change \\
\hline Chemokine (C-X-C motif) ligand 12 (stromal cell-derived factor 1 ) & CXCL12 & -212 \\
\hline Endothelin 1 & EDN1 & 2.55 \\
\hline LY6/PLAUR domain containing 3 & LYPD3 & -1.17 \\
\hline Matrix metallopeptidase 3 (stromelysin 1, progelatinase) & MMP3 & 2.26 \\
\hline Plasminogen activator, urokinase & PLAU & 1.07 \\
\hline 4. Regulation of cellular growth & Symbol & $\log 2$ change \\
\hline Cyclin D1 & CCND1 & 1.03 \\
\hline v-fos FBJ murine osteosarcoma viral oncogene homolog & FOS & -1.6 \\
\hline Mitogen-activated protein kinase kinase kinase 8 & MAP3K8 & -1.2 \\
\hline Growth differentiation factor 8 (myostatin) & GDF8 (MTSN) & -2.72 \\
\hline Uncoupling protein 2 (mitochondrial, proton carrier) & UCP2 & 1.4 \\
\hline WNT1 inducible signaling pathway protein 1 & WISP1 & 1.04 \\
\hline
\end{tabular}

All experiments were performed in duplicate. The expression levels were normalized to five internal control genes, $\log 2$ change was calculated as $-\Delta \Delta \mathrm{Ct}$

Migration capacity and expression of MMPs in tumor-derived $M F s$. As gene expression data indicated that a number of the genes exhibiting altered expression levels in tumor-associated MFs are involved in the regulation of cellular growth and metastasis, the expression analysis was extended to matrix-modifying factors. As MFs can secrete MMP enzymes into their surroundings, the MMP expression pattern of MFs was examined to see whether there is a difference in this respect between the esophageal tumor- and normal tissue-derived MFs.

Using RT-qPCR significantly increased levels of mRNA corresponding to MMP3, MMP10 and MMP12 were detected in MFs isolated from the esophageal tumor compared with the normal tissue MFs $(\mathrm{P}<0.01)$, however no difference was demonstrated in MMP1 and MMP2 levels (Fig. 3A). Since the secreted gelatinase MMP2 localizes on the surface of the migrating cells (23) and accumulates mainly on the leading edge of invasive tumors (24), in-gel zymography was used to test gelatinolytic activity in MF cell lysates and conditioned cell media. Although zymograms indicated no significant differences in MMP2 activities between cell lysates of esophageal tumor-derived and normal tissue MFs, conditioned media of the tumor-associated cells exhibited markedly higher MMP2 activity compared with the medium of normal MFs (Fig. 3B). Altogether these results indicate that MFs in the tumor tissue are programmed to express and secrete higher amounts of various MMP enzymes than normal tissue residing counterparts. This feature can contribute to the capability of tumor stroma residing MFs of degrading pericellular ECM, as well as to promoting tumor invasion and metastasis.

In addition to the MMP expression profile and activity, the migratory capacity of esophageal tumor- and normal tissue-derived MFs was also investigated. For this, scratch wound assays were performed and the migratory activity of MFs within a 24-h time frame was compared (Fig. 3C). The motility of normal MFs was defined as $100 \%$ and expressed data obtained for tumor-derived MFs was defined as normalized migration rate. It was demonstrated that the tumor-derived MFs migrated significantly more $(153.09 \% \pm 2.12)$ compared with their normal counterparts $(100 \% \pm 2.39$; $\mathrm{P}<0.05$; Fig. $3 \mathrm{C})$, suggesting that an elevated migratory capacity is an acquired functional feature of the tumor-residing MF phenotype.

To verify that the observed functional differences between normal tissue and tumor-residing MFs populations of the same individual are not limited to one patient but can be considered widespread, and to draw a general conclusion from the results of the present study, additional MF cultures were established from tissue specimens of other patients bearing tumors in diverse regions of the gastrointestinal tract, namely individuals with cecum, sigmoid colon or rectum carcinoma. The 
A

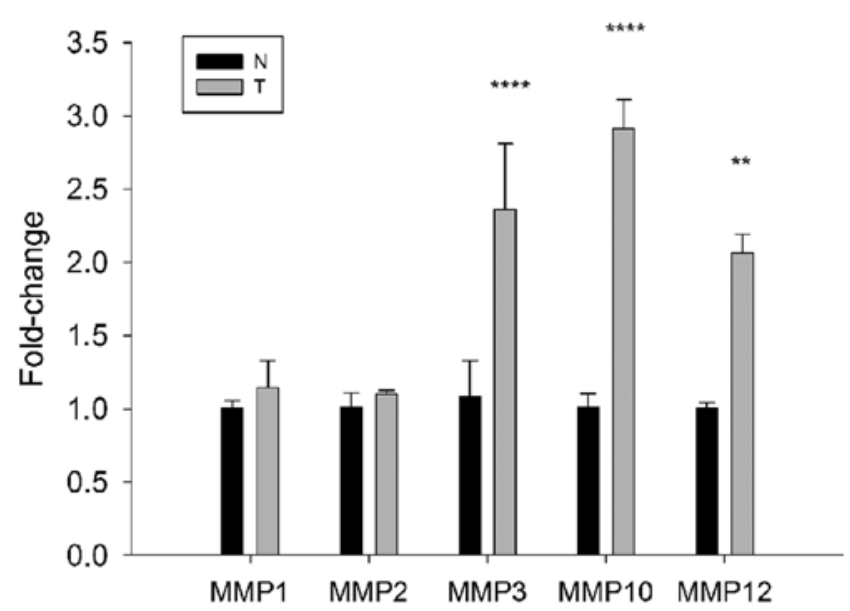

B
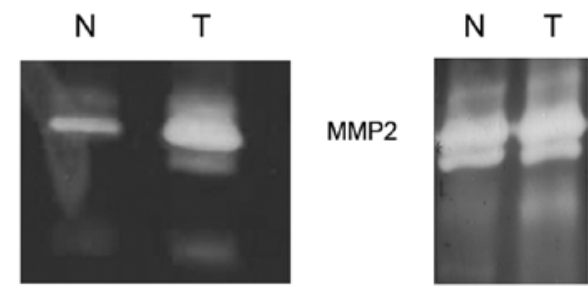

Medium

Cell lysate

\section{C}

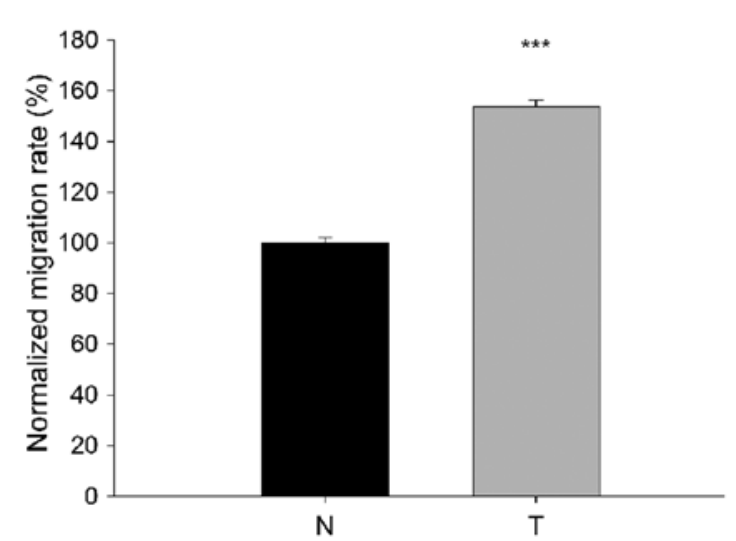

Figure 3. Expression and activity of matrix metalloproteases and migration capacity of tumor-associated MFs. Quantitative polymerase chain reaction (A) data demonstrates the expression of MMP1, MMP2, MMP3, MMP10 and MMP12 in the tumor-derived MFs and in the control cells. The expression levels were normalized to the expression of the control sample. Expression of MMP3, MMP10 and MMP12 was significantly elevated in tumor-derived MFs compared to control cells. ${ }^{* * * *} \mathrm{P}<0.0001$ and ${ }^{* *} \mathrm{P}<0.01$; two way ANOVA followed by Tukey's HSD post hoc multiple comparison test. No difference was observed for MMP1 and MMP2 expression. In-gel zymography was performed on tumor-associated and control MFs to determine MMP gelatinase activity (B). Slight difference in MMP2 enzyme activity was detected between tumor-derived and adjacent normal MF cell lysates. However, MMP2 activity was markedly higher in conditioned cell media of tumor-associated MFs compared with that of normal tissue-derived MFs. On the representative zymograms the upper band reflects the zymogen form of MMP2 (proform), while the lower band corresponds to the active form of MMP2. No MMP9 activity was detected in either MF culture. Migratory capacity of tumor-associated and adjacent normal tissue-derived MFs was assessed by wound healing assay (C). Cells that migrated into the wound area were counted $24 \mathrm{~h}$ following scratching Motility of the normal MFs was defined as $100 \%$. Migration capacity of tumor-derived MFs was significantly higher compared with normal cells $(153.09 \pm 2.12$ vs. $100 \pm 2.39)$ indicated by the summarized migration rate ${ }^{* * *} \mathrm{P}<0.001$; Student's t-test. MMP, matrix metalloproteinase; MF, myofibroblast. matching tumor-derived and normal tissue-derived MF pairs were subjected to a scratch wound assay and RNA extraction to determine migration activity and MMP expression levels. Pair-wise comparisons of tumor- and normal tissue-derived MFs revealed that tumor-originating MFs migrated significantly more compared their normal counterparts $(\mathrm{P}<0.01$; Fig. 4A and B). Using these MF cultures, differences were demonstrated in the expression levels of various MMPs (represented as fold-change in Fig. 4C), proteases that can modulate cell-matrix interactions and facilitate cell mobilization, between stromal and normal MFs. A rather analogous behavior of tumor-residing MFs within the whole gastrointestinal tract is represented, therefore, it is feasible to suggest that these traits acquired by MFs in the tumor microenvironment can in fact develop generally in the tumor stroma and are not restricted to one single patient. Although patient-to-patient individual variations cannot be excluded, similar acquired features of stromal MFs in esophagus, cecum, sigmoid colon and rectum tumor have been demonstrated.

\section{Discussion}

MFs are important stromal cells that define the tumor tissue microenvironment through secretion of ECM components, growth factors, cytokines, proteases and protease inhibitors $(25,26)$. Through direct or indirect actions between MFs and transformed cancer cells the newly established niche supports the active remodeling of the physical environment, which will ultimately stimulate cancer cell proliferation and dissemination (27). The functional features of tumor-residing MFs are currently studied extensively, nonetheless, knowledge on the genetic and epigenetic background, as well as on the transcriptomic features of the evolving stromal MF phenotypes remains limited. A comparative analysis of MFs obtained from the tumor tissue and from tumor-adjacent normal tissue of an esophageal cancer patient was performed, in order to identify specific features of the exhibited MF phenotype in the tumor microenvironment. Finally, specific acquired features on other gastrointestinal tract tumor-derived MFs were verified. Appropriate examination of MF-specific properties required the establishment of pure MF cell cultures from surgically resected human samples.

To gain information on the genetic status of stromal MFs, next generation sequencing was performed to detect the occurrence of nucleotide variants in a set of most frequently mutated cancer genes. As expected, over $255 \mathrm{kbp}$ ( 1 variant per kbp) was demonstrated. Among these, normal tissue-derived and tumor-associated MFs carried 22 relevant germline SNPs (Table I) predicted to be functionally significant. A few genes (ERCC5, BRCA2, MSH6 and SLX4) were affected by more than one SNP. A total of 4 variants were also identified that were present only in tumor-associated MF samples and 11 variants that were present in the tumor tissue but not in the adjacent normal MF samples (Table II). The TP53 that were detected to be present with $14.92 \%$ allele frequency in the tumor tissue has already been associated with tumors in various primary sites including the esophagus (reference in ClinVar database).

The genetic analysis in the present study indicated low occurrence of somatic variants in tumor-associated MF samples and that normal tissue- and tumor-derived MFs carry 
A

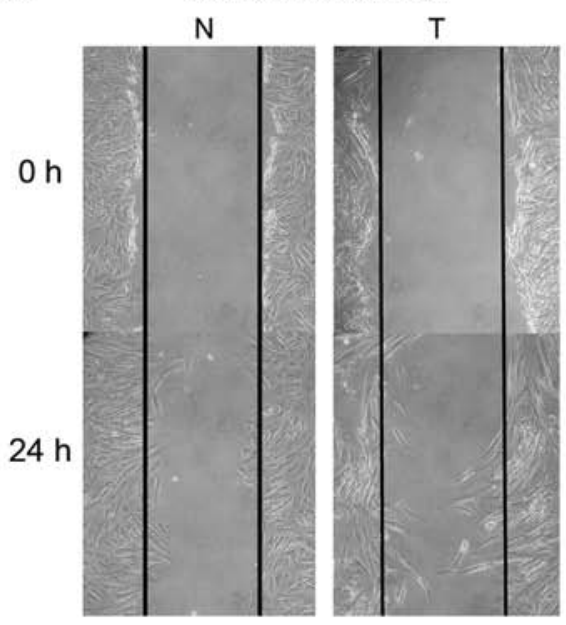

Sigmoid colon carcinoma

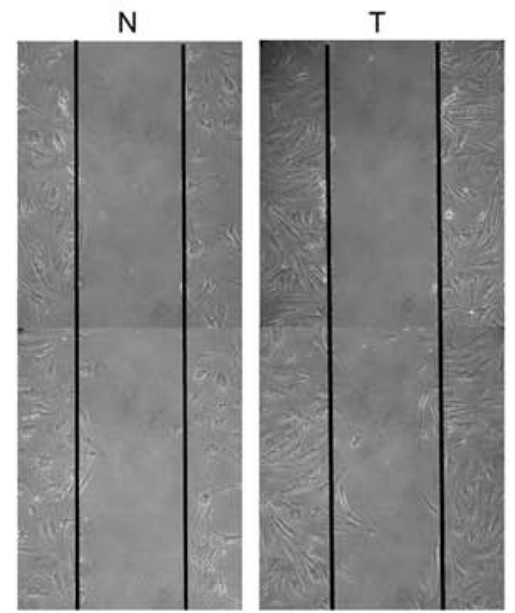

Rectum carcinoma

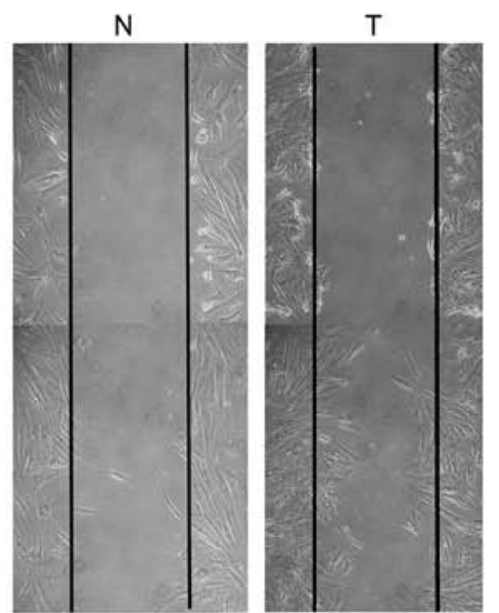

B

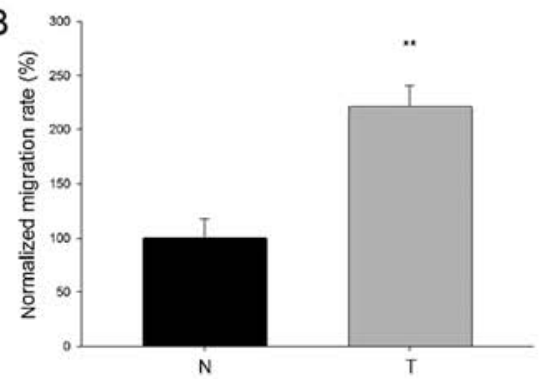

C

\begin{tabular}{|c|c|c|}
\hline \multirow{2}{*}{} & $\mathrm{N}$ & $\mathrm{T}$ \\
\cline { 2 - 3 } & \multicolumn{2}{|c|}{ fold-change } \\
\hline MMP1 & 1 & 0.8 \\
\hline MMP2 & 1 & 0.9 \\
\hline MMP3 & 1 & 4.2 \\
\hline MMP10 & 1 & 0.3 \\
\hline MMP12 & 1 & 1.9 \\
\hline
\end{tabular}

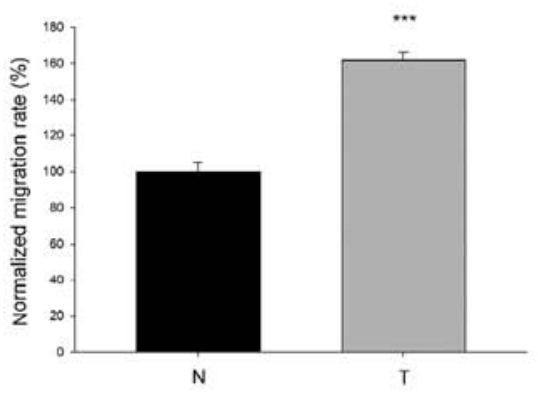

\begin{tabular}{|c|c|c|}
\hline \multirow{2}{*}{} & $\mathrm{N}$ & $\mathrm{T}$ \\
\cline { 2 - 3 } & \multicolumn{2}{|c|}{ fold-change } \\
\hline MMP1 & 1 & 1.5 \\
\hline MMP2 & 1 & 1.0 \\
\hline MMP3 & 1 & 3.5 \\
\hline MMP10 & 1 & 9.8 \\
\hline MMP12 & 1 & 10.5 \\
\hline
\end{tabular}

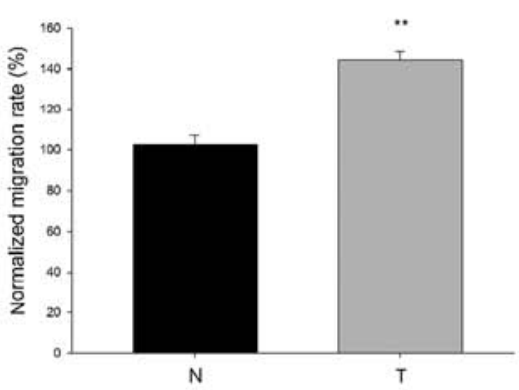

\begin{tabular}{|c|c|c|}
\hline \multirow{2}{*}{} & $\mathrm{N}$ & $\mathrm{T}$ \\
\cline { 2 - 3 } & \multicolumn{2}{|c|}{ fold-change } \\
\hline MMP1 & 1 & 2.0 \\
\hline MMP2 & 1 & 0.5 \\
\hline MMP3 & 1 & 6.3 \\
\hline MMP10 & 1 & 5.4 \\
\hline MMP12 & 1 & 4.6 \\
\hline
\end{tabular}

Figure 4. Migration capacity and relative expression levels of various MMPs of tumor-derived and normal MF obtained from diverse regions of the gastrointestinal tract. Representative images of scratch wound assays demonstrated migration of MF cells into the wound area $24 \mathrm{~h}$ following scratching (A). Migration rate was calculated based on the number of MF cells in the wound zone and was normalized to the motility of the normal tissue-derived MFs (B). Higher number of MFs could be counted within the wound area $24 \mathrm{~h}$ following scratching in the tumor-associated MF samples, therefore tumor-derived cells exhibited a greater migratory capacity compared with the normal MFs ${ }^{* * *} \mathrm{P}=0.01$ for cecum-derived $\mathrm{MFs},{ }^{* * *} \mathrm{P}<0.001 \mathrm{for}$ sigmoid colon-derived $\mathrm{MFs}$ and ${ }^{* * *} \mathrm{P}=0.002$ for rectum-derived MFs, t-test). (C) Relative mRNA levels of matrix metalloproteases of tumor-associated and normal MFs. Tables demonstrate the relative expression of MMP1, MMP2, MMP3, MMP10 and MMP12 in the tumor-derived MFs compared with control cells based on quantitative polymerase chain reaction experiments. The expression levels of MMPs were defined as 1 for the control sample and the mRNA levels detected in tumor-derived MFs are indicated as fold-change. MMP, matrix metalloproteinase; MF, myofibroblast; T, tumor-associated; N, normal.

similar numbers of unique somatic mutations, suggesting that mutation frequency is not elevated drastically in tumor-associated MFs.

This lack of notable genetic alterations in tumor-associated compared with the control MFs suggests that genetic variations most probably cannot explain the observed differences, including the largely elevated MF number, the severely damaged MF architecture and the meshwork-like structures created by tumor-residing MFs. Instead, in light of these data, epigenetic mechanisms are responsible for the emergence of the stromal MF phenotype. Indeed, global DNA hypomethylation that may have a relevant role in cancer progression has already been demonstrated in cancer-associated MFs (28).
It is well-known, that in addition to DNA methylation, alterations in the acetylation or methylation level of specific lysine $(\mathrm{K})$ side chains of histone proteins, established by histone modifying enzyme complexes, can lead to chromatin modifications, thereby to major variations in the gene expression pattern and consequently to morphological, and functional alterations of a given cell (29-31). Alterations in the global levels of numerous epigenetic histone marks were examined and shifts were detected in the level of specific acetylated and methylated histone proteins between normal tissue- and esophageal tumor-derived MFs. The observed alterations, including decreased levels of trimethylated H3K9 and acetylated H4K16 in tumor-associated MFs may affect chromatin 
structure, which can at least partly serve as the underlying cause of the altered morphology of tumor-derived MFs.

In transformed cells, alterations in the expression of hundreds of genes occur throughout tumorigenesis and tumor invasion (32-34). Although MFs are non-transformed cells, their expressional profile is expected to adapt to the undergoing morphological and functional alterations within the tumor microenvironment $(35,36)$. Elevated gene expression level of CCND1 were observed in tumor-derived MFs compared with normal MFs. Significantly increased expression of CCNDI has previously been identified in stromal fibroblasts of patients with invasive breast cancer, characterized by enhanced cancer growth, restrained apoptosis and poor patient outcome (37). In the present study it was hypothesized that the observed increased level of the CCNDI transcript is correlated with the elevated number of MF cells within the tumor tissue. Similarly, WISP1, a downstream component in the WNT1 signaling pathway [believed to be relevant to malignant transformation (38)] was also expressed at a high level in MF cells isolated from the tumor. The encoded protein attenuates p53-mediated apoptosis and binds to members of small leucine-rich proteoglycans present in the ECM therefore preventing the inhibitory activity of decorin and biglycan in tumor cell proliferation $(39,40)$. The modulation of apoptotic mechanisms in tumor residing MFs is also indicated by the altered expression of apoptosis-associated BCL2 and FOS in these cells. The increased expression of $U C P 2$, a critical regulator of cellular metabolism, involved in the tumor-promoting metabolic shift during cell transformation (41), is also detectable in MFs. These cells must also participate in the complex metabolism of the tumor tissue by promoting cancer cells to overcome energy depletion due to the Wartburg effect. Finally, expression of hypoxia- and angiogenesis-linked ENPP2, HO- 1 and PTN genes were decreased in tumor-derived MFs compared with normal counterparts (Table III). PTN is a small secreted cytokine and it has a potent role in tumor growth progression, therefore, lower level of PTN mRNA in tumor-associated compared with normal MFs was somewhat surprising, however a study on prostate tumor CAFs reported a similar results (42).

Although TGF $\beta$ signaling can drive tumorigenesis and it is also the most capable factor in controlling MF differentiation, proliferation, and the interactions with the cellular microenvironment $(43,44)$, notable differences were not demonstrated between MFs of different origins in the expression of TGF $\beta$ signaling pathway components. The only member of the TGF $\beta$ protein family with lower levels of mRNA in tumor-derived MFs corresponded to the secreted growth differentiation factor GDF8/MSTN. This protein is a negative regulator of skeletal muscle development and its high expression is associated with cancer cachexia (45). Decreased level of MSTN was also detectable in higher grade breast cancers and MSTN supplementation reduced the viability, and the migratory capacity of MCF-7 breast adenocarcinoma cell line (46). Furthermore, lower levels of mRNA corresponding to $M A P 3 K 8$ in tumor-associated MFs. This observation is also in agreement with previous results on the altered secretory profile of intestinal MFs of $M A P 3 K 8$ mutant mice, developing increased numbers and sizes of tumors, associated with enhanced epithelial proliferation and decreased apoptosis (Table III).
In tumor-derived MFs expression differences of various genes associated with metastasis were also observed. Among these, increased expression of EDN1 in tumor-derived MFs has been verified. EDN1 is a metastasis-involved secreted peptide exhibiting a strong stimulatory activity on cancer and stromal cell proliferation and migration within the tumor microenvironment (47). A low expression level of HMOX1 was detected in MFs originating from the tumors. As HMOX1 is a negative regulator of EDN 1 production, this lower expression of HMOX1 can explain the increased transcript levels of EDN1 (48). Like EDN1, elevated expression of MMP3 and $P L A U$ has been detected in tumor-associated MFs compared with normal tissue-derived MFs (Table III). These two genes encode secreted zinc and serine protease enzymes, which following activation are partly responsible for the degradation of a number ECM proteins, including fibronectin, laminin, collagens, further supporting the active assistance of stromal MFs in tumor dissemination and metastasis (49). On the other hand, TaqMan array data indicated lower transcript levels of LYPD3 in tumor-derived MFs, which is not surprising in the view of a recent study on the differential diagnosis of epithelial malignancies, where the authors revealed that LYPD3 expression is elevated only in esophageal squamous cell carcinoma, but not in adenocarcinoma derived from esophagus tissue (50). Also in agreement with a previous study, lower expression of the chemokine CXCL12 was exhibited in tumor-derived MFs, demonstrated to be a prominent feature of clinical breast cancer lesions and together with elevated $C X C R 7$ levels it correlated significantly with poor survival (51).

Tumor cells adopt the ability to migrate from the primary tumor site by becoming motile and obtain plasticity to mechanically navigate the tumor stroma. The invasion process requires enzymes capable of remodeling the ECM protein scaffold to make room for cancer cell movement. The production of ECM remodeling proteases promotes cell invasion and motility by the dynamical degradation of the pericellular ECM (52). When activated, these proteases, including MMPs, cleave basement membrane components and multiadhesion proteins. In this way, MMPs can modulate cell-matrix interactions and facilitate cell mobilization, which ultimately supports cell migration $(53,54)$. In fact, strong correlation has already been proposed between elevated expression levels of certain MMPs in tumor tissues and advanced tumor stages (TNM grading), increased metastasis, and poor prognosis $(16,17)$. Based on the mRNA expression, as well as on the activity of various MMPs, a modified MMP profile of tumor-derived MFs compared to normal MFs was observed. Furthermore, strongly correlated with the altered expression and secretion of proteases it was demonstrated that the tumor-derived MFs also migrated more compared with their normal counterparts, revealing another acquired functional feature of the tumor-residing MF phenotype. These results on altered MMP expression and enhanced migration of stromal MFs have been supported and strengthened by tumor- and normal tissue-derived MF pairs obtained from other regions of the gastrointestinal tract, namely from the cecum, sigmoid colon and rectum. Therefore, it is feasible to suggest that MFs in the tumor microenvironment assist cancer cell movement and by acquiring migratory capacity, these stromal cells have the potential to move collectively with cancer cells to promote the invasiveness of cancer cells in the tumor leading edge (55). 
Taken together, the results of the present study indicate that the observed morphological, gene expressional and concomitant functional alterations of MFs in the tumor microenvironment are definitely not due to genetic alterations but are more probably associated with epigenetic modifications. Nonetheless, similarly to other attempts trying to correlate histone modifications with altered RNA production level a careful analysis is warranted to distinguish causes and consequences.

In conclusion, in the present study human MFs obtained from gastrointestinal cancers were compared with those residing in adjacent normal tissue of individual patients to identify features of the exhibited MF phenotype that were acquired in the tumor microenvironment. MF cells were analyzed for differences in morphology, gene expression profile and function with the aim to associate observed variations with underlying genetic and/or epigenetic differences. It was demonstrated that mutation frequency was not elevated in tumor-derived MFs. Histone acetylation and methylation on the other hand can be more relevant in the development of gene expressional and functional alterations during the evolution of the stromal MF phenotype. The results of the present study also demonstrated that though correlations between transcriptional, functional and epigenetic results can be drawn, general conclusions have to be considered very carefully. Since the present study directly compared features of MFs of normal and tumor tissues of various gastrointestinal cancer patients, it was hypothesized that the present study's results are a valuable contribution to the knowledge on the impact of MFs in supporting tumor progression.

\section{Acknowledgements}

The authors would like to acknowledge the assistance of Ms. Edina Pataki and Mrs. Zoltán Fuksz.

\section{Funding}

The present study was funded by the Hungarian National Development Agency (TÁMOP grant no. 4.2.2-08/1/20080013, Hungarian Academy of Sciences) and by the MTA-SZTE Momentum Grant (grant no. LP2014-10/2014) and by GINOP-2.3.2-15-2016-00020.

\section{Availability of data and materials}

Data supporting the results of the present study are available upon request.

\section{Authors' contributions}

IH carried out the transcriptional and epigenetic studies, analyzed the data and performed the statistical analysis. LB carried out next generation sequencing and analyzed the sequencing data. MC performed the analysis of the clinical data. DK performed the scratch assays. AS carried out experiments on matrix metalloproteinases; LT was responsible for conducting the histopathological analysis; GL performed patient surgery and provided resection samples. ZR made a substantial contribution to the interpretation of the data and revised the manuscript; $\mathrm{PH}$ contributed to the conception and design of the project and coordinated the associated clinical and research activities. IMB designed the project, coordinated the molecular genetic studies and revised the manuscript; MK carried out immunoblotting, substantially contributed to the analysis and interpretation of the data and drafted the manuscript. All authors read and approved the final manuscript.

\section{Ethics approval and consent to participate}

The patient gave written consent. The study was approved by the Ethics Committee of the University of Szeged, Hungary. All surgical patients gave informed consent. The scheme of the experiments complies with the ethics of research and agrees with the declaration of the Medical World Federation proclaimed in Helsinki in 1964. Human Investigation Board of the University of Szeged. Date: March 20 2006. South Sefton Research Ethics Committee PO/JO/EC.90.03-2 NHS Trust Research Ethics Committee Ref.: EC 90.03.

\section{Patient consent for publication}

The patient gave written consent.

\section{Competing interests}

The authors declare that they have no competing interests.

\section{References}

1. Hanahan D and Weinberg RA: Hallmarks of cancer: The next generation. Cell 144: 646-674, 2011.

2. Hanahan D and Coussens LM: Accessories to the crime: Functions of cells recruited to the tumor microenvironment. Cancer Cell 21: 309-322, 2012.

3. Wang M, Zhao J, Zhang L, Wei F, Lian Y, Wu Y, Gong Z, Zhang S, Zhou J, Cao K, et al: Role of tumor microenvironment in tumorigenesis. J Cancer 8: 761-773, 2017.

4. Polyak K, Haviv I and Campbell IG: Co-evolution of tumor cells and their microenvironment. Trends Genet 25: 30-38, 2009.

5. Shiga K, Hara M, Nagasaki T, Sato T, Takahashi H and Takeyama H: Cancer-associated fibroblasts: their characteristics and their roles in tumor growth. Cancers (Basel) 7: 2443-2458, 2015.

6. Orimo A and Weinberg RA: Heterogeneity of stromal fibroblasts in tumors. Cancer Biol Ther 6: 618-619, 2007.

7. Eyden B: The myofibroblast: Phenotypic characterization as a prerequisite to understanding its functions in translational medicine. J Cell Mol Med 12: 22-37, 2008.

8. Gabbiani G: The biology of the myofibroblast. Kidney Int 41: 530-532, 1992.

9. Hinz B, Phan SH, Thannickal VJ, Prunotto M, Desmoulière A, Varga J, De Wever O, Mareel M and Gabbiani G: Recent developments in myofibroblast biology: Paradigms for connective tissue remodeling. Am J Pathol 180: 1340-1355, 2012.

10. Hinz B, Phan SH, Thannickal VJ, Galli A, Bochaton-Piallat ML and Gabbiani G: The myofibroblast: One function, multiple origins. Am J Pathol 170: 1807-1816, 2007.

11. Desmoulière $A$, Guyot $C$ and Gabbiani G: The stroma reaction myofibroblast: A key player in the control of tumor cell behavior. Int J Dev Biol 48: 509-517, 2004.

12. Pietras K and Ostman A: Hallmarks of cancer: Interactions with the tumor stroma. Exp Cell Res 316: 1324-1331, 2010.

13. Grugan KD, Miller CG, Yao Y, Michaylira CZ, Ohashi S, Klein-Szanto AJ, Diehl JA, Herlyn M, Han M, Nakagawa H, et al: Fibroblast-secreted hepatocyte growth factor plays a functional role in esophageal squamous cell carcinoma invasion. Proc Natl Acad Sci USA 107: 11026-11031, 2010. 
14. Couto N, Caja S, Maia J, Strano Moraes MC and Costa-Silva B Exosomes as emerging players in cancer biology. Biochimie S0300-9084(18)30067-1, 2018

15. De Wever O, Demetter P, Mareel M and Bracke M: Stromal myofibroblasts are drivers of invasive cancer growth. Int J Cancer 123: 2229-2238, 2008.

16. Bauvois B: New facets of matrix metalloproteinases MMP-2 and MMP-9 as cell surface transducers: Outside-in signaling and relationship to tumor progression. Biochim Biophys Acta 1825: 29-36, 2012.

17. Shay G, Lynch CC and Fingleton B: Moving targets: Emerging roles for MMPs in cancer progression and metastasis. Matrix Biol 44-46: 200-206, 2015.

18. Mehner C and Radisky DC: Triggering the landslide: The tumor-promotional effects of myofibroblasts. Exp Cell Res 319: $1657-1662,2013$

19. Gargus M, Niu C, Vallone JG, Binkley J, Rubin DC and Shaker A: Human esophageal myofibroblasts secrete proinflammatory cytokines in response to acid and Toll-like receptor 4 ligands. Am J Physiol Gastrointest Liver Physiol 308: G904-G923, 2015.

20. Czepán M, Rakonczay Z Jr, Varró A, Steele I, Dimaline R, Lertkowit N, Lonovics J, Schnúr A, Biczó G, Geisz A, et al: NHE1 activity contributes to migration and is necessary for proliferation of human gastric myofibroblasts. Pflugers Arch 463: 459-475, 2012

21. Livak KJ and Schmittgen TD: Analysis of relative gene expression data using real-time quantitative PCR and the 2(-Delta Delta C(T)) Method. Methods 25: 402-408, 2001.

22. Bensadoun A and Weinstein D: Assay of proteins in the presence of interfering materials. Anal Biochem 70: 241-250, 1976

23. Jiao Y, Feng X, Zhan Y, Wang R, Zheng S, Liu W and Zeng X: Matrix metalloproteinase-2 promotes $\alpha v \beta 3$ integrin-mediated adhesion and migration of human melanoma cells by cleaving fibronectin. PLoS One 7: e41591, 2012.

24. Yu CF, Chen FH, Lu MH, Hong JH and Chiang CS: Dual roles of tumour cells-derived matrix metalloproteinase 2 on brain tumour growth and invasion. Br J Cancer 117: 1828-1836, 2017.

25. Kalluri R: The biology and function of fibroblasts in cancer. Nat Rev Cancer 16: 582-598, 2016.

26. Yazdani S, Bansal R and Prakash J: Drug targeting to myofibroblasts: Implications for fibrosis and cancer. Adv Drug Deliv Rev 121: 101-116, 2017.

27. Holmberg C, Ghesquière B, Impens F, Gevaert K, Kumar JD, Cash N, Kandola S, Hegyi P, Wang TC, Dockray GJ, et al: Mapping proteolytic processing in the secretome of gastric cancer-associated myofibroblasts reveals activation of MMP-1, MMP-2, and MMP-3. J Proteome Res 12: 3413-3422, 2013.

28. Jiang L, Gonda TA, Gamble MV, Salas M, Seshan V, Tu S, Twaddell WS, Hegyi P, Lazar G, Steele I, et al: Global hypomethylation of genomic DNA in cancer-associated myofibroblasts. Cancer Res 68: 9900-9908, 2008.

29. Baxter E, Windloch K, Gannon F and Lee JS: Epigenetic regulation in cancer progression. Cell Biosci 4: 45, 2014.

30. Zhang G and Pradhan S: Mammalian epigenetic mechanisms. IUBMB Life 66: 240-256, 2014.

31. Albrengues J, Bertero T, Grasset E, Bonan S, Maiel M, Bourget I, Philippe C, Herraiz Serrano C, Benamar S, Croce O, et al: Epigenetic switch drives the conversion of fibroblasts into proinvasive cancer-associated fibroblasts. Nat Commun 6: 10204,2015.

32. Andrade VP, Morrogh M, Qin LX, Olvera N, Giri D, Muhsen S, Sakr RA, Schizas M, Ng CK, Arroyo CD, et al: Gene expression profiling of lobular carcinoma in situ reveals candidate precursor genes for invasion. Mol Oncol 9: 772-782, 2015.

33. Wu Y, Wang X, Wu F, Huang R, Xue F, Liang G, Tao M, Cai P and Huang Y: Transcriptome profiling of the cancer, adjacent non-tumor and distant normal tissues from a colorectal cancer patient by deep sequencing. PLoS One 7: e41001, 2012.

34. Coskunpinar E, Oltulu YM, Orhan KS, Tiryakioglu NO, Kanliada D and Akbas F: Identification of a differential expression signature associated with tumorigenesis and metastasis of laryngeal carcinoma. Gene 534: 183-188, 2014.

35. Berdiel-Acer M, Sanz-Pamplona R, Calon A, Cuadras D, Berenguer A, Sanjuan X, Paules MJ, Salazar R, Moreno V, Batlle E, et al: Differences between CAFs and their paired NCF from adjacent colonic mucosa reveal functional heterogeneity of CAFs, providing prognostic information. Mol Oncol 8: 1290-1305, 2014.

36. Navab R, Strumpf D, Bandarchi B, Zhu CQ, Pintilie M, Ramnarine VR, Ibrahimov E, Radulovich N, Leung L, Barczyk M, et al: Prognostic gene-expression signature of carcinoma-associated fibroblasts in non-small cell lung cancer. Proc Natl Acad Sci USA 108: 7160-7165, 2011.
37. Pestell TG, Jiao X, Kumar M, Peck AR, Prisco M, Deng S, Li Z, Ertel A, Casimiro MC, Ju X, et al: Stromal cyclin D1 promotes heterotypic immune signaling and breast cancer growth. Oncotarget 8: 81754-81775, 2017.

38. Wu J, Long Z, Cai H, Du C, Liu X, Yu S and Wang Y: High expression of WISP1 in colon cancer is associated with apoptosis, invasion and poor prognosis. Oncotarget 7: 49834-49847, 2016.

39. Desnoyers L, Arnott D and Pennica D: WISP-1 binds to decorin and biglycan. J Biol Chem 276: 47599-47607, 2001.

40. Su F, Overholtzer M, Besser D and Levine AJ: WISP-1 attenuates p53-mediated apoptosis in response to DNA damage through activation of the Akt kinase. Genes Dev 16: 46-57, 2002.

41. Sreedhar A, Petruska P, Miriyala S, Panchatcharam M and Zhao Y: UCP2 overexpression enhanced glycolysis via activation of PFKFB2 during skin cell transformation. Oncotarget 8: 95504-95515, 2017.

42. Orr B, Vanpoucke G, Grace OC, Smith L, Anderson RA, Riddick AC, Franco OE, Hayward SW and Thomson AA: Expression of pleiotrophin in the prostate is androgen regulated and it functions as an autocrine regulator of mesenchyme and cancer associated fibroblasts and as a paracrine regulator of epithelia. Prostate 71: 305-317, 2011.

43. Costanza B, Umelo IA, Bellier J, Castronovo V and Turtoi A Stromal Modulators of TGF- $\beta$ in cancer. J Clin Med 6: 6, 2017.

44. Tian M, Neil JR and Schiemann WP: Transforming growth factor- $\beta$ and the hallmarks of cancer. Cell Signal 23: 951-962, 2011.

45. Miyamoto Y, Hanna DL, Zhang W, Baba H and Lenz HJ: Molecular pathways: Cachexia signaling - a targeted approach to cancer treatment. Clin Cancer Res 22: 3999-4004, 2016.

46. Wallner C, Drysch M, Becerikli M, Jaurich H, Wagner JM, Dittfeld S, Nagler J, Harati K, Dadras M, Philippou S, et al: Interaction with the GDF8/11 pathway reveals treatment options for adenocarcinoma of the breast. Breast 37: 134-141, 2018.

47. Rosanò L and Bagnato A: Endothelin therapeutics in cancer: Where are we? Am J Physiol Regul Integr Comp Physiol 310: R469-R475, 2016.

48. Bakrania BA, Spradley FT, Satchell SC, Stec DE, Rimoldi JM, Gadepalli RSV and Granger JP: Heme oxygenase-1 is a potent inhibitor of placental ischemia-mediated endothelin-1 production in cultured human glomerular endothelial cells. Am J Physiol Regul Integr Comp Physiol 314: R427-R432, 2018.

49. Barajas-CastañedaLM,Cortés-GutiérrezE,García-RodríguezFM, Campos-Rodríguez R, Lara-Padilla E, Enríquez-Rincón F, Castro-Mussot ME and Figueroa-Arredondo P: Overexpression of MMP-3 and uPA with diminished PAI-1 related to metastasis in ductal breast cancer patients attending a public hospital in Mexico City. J Immunol Res 2016: 8519648, 2016.

50. Wang W, Ding YQ, Li ZG, Han HX and Yang L: Expression and diagnostic application of $\mathrm{C} 4.4 \mathrm{~A}$ protein in squamous cell carcinoma and adenocarcinoma. Zhonghua Bing Li Xue Za Zhi 35: 277-280, 2006 (In Chinese).

51. Yu PF, Huang Y, Xu CL, Lin LY, Han YY, Sun WH, Hu GH, Rabson AB, Wang Y and Shi YF: Downregulation of CXCL12 in mesenchymal stromal cells by TGF $\beta$ promotes breast cancer metastasis. Oncogene 36: 840-849, 2017.

52. Hua H, Li M, Luo T, Yin Y and Jiang Y: Matrix metalloproteinases in tumorigenesis: An evolving paradigm. Cell Mol Life Sci 68: 3853-3868, 2011.

53. Deryugina EI and Quigley JP: Matrix metalloproteinases and tumor metastasis. Cancer Metastasis Rev 25: 9-34, 2006.

54. Koyama S: Coordinate cell-surface expression of matrix metalloproteinases and their inhibitors on cancer-associated myofibroblasts from malignant ascites in patients with gastric carcinoma. J Cancer Res Clin Oncol 131: 809-814, 2005.

55. Sameni M, Anbalagan A, Olive MB, Moin K, Mattingly RR and Sloane BF: MAME models for 4D live-cell imaging of tumor: Microenvironment interactions that impact malignant progression. J Vis Exp 60: 3661, 2012.

This work is licensed under a Creative Commons Attribution-NonCommercial-NoDerivatives 4.0 International (CC BY-NC-ND 4.0) License. 